\title{
EXTRAMAMMARY PAGET'S DISEASE: A CASE REPORT
}

\author{
Anita Shah, ${ }^{1}$ Yogesh Poudel, ${ }^{2}$ Anuj Poudel ${ }^{1}$
}

\section{ABSTRACT}

A 60- year-old man presented with four year history of a non- healing rash. The rash was pruritic and painless. He had previously been treated empirically with oral and topical antibiotics, topical antifungal agents, and topical glucocorticoids without improvement. The physical examination revealed an erythematous plaque with superficial white scale affecting the skin of the groin and scrotum. Skin biopsy and histopathology revealed epidermal infiltration by large atypical cells that had eosinophilic cytoplasm and prominent nucleoli, findings were consistent with Pagets disease. Extramammary Paget's disease (EMPD) is an intraepithelial adenocarcinoma that is sometimes misdiagnosed as dermatitis clinically. It most commonly involves the vulva and in perianal skin, scrotum, penis and axilla. The patient was kept on regular surveillance. The patient has increased intensity of itching and increase in size of lesion after six months of diagnosis.

KEYWORDS Extramammary Paget's disease, Histopathology, Non-healing rash.

1 Department of Pathology, Universal College of Medical Sciences, Bhairahawa, Nepal

2 Consultant Dermatologist, Sarnath Skin Centre, Bhairahawa, Nepal

DOI: http//doi.org/10.3126/jucms.v8i1.29847

\author{
For Correspondence \\ Dr. Anita Shah \\ Department of Pathology \\ Universal College of Medical Sciences \\ Bhairahawa, Nepal \\ Email: anitashah50bwa@gmail.com
}




\section{INTRODUCTION}

Extramammary Paget's Disease (EMPD) was recognized as an entity over a decade after Paget's disease was first described. EMPD should be considered in all patients with a picture of chronic genital dermatitis. ${ }^{1}$ It most commonly affects the vulva in female, less commonly the male genital area or perianal area, and, in exceptional cases, the axillae, the region of the ceruminal glands, or that of Moll glands. Thus, EMPD involves areas in which apocrine glands are normally encountered. ${ }^{2}$ EMPD accounts for $1 \%$ of all neoplasms in the anogenital area. ${ }^{3}$

We present here a case of EMPD with enlarging and itchy lesion on the suprapubic area over a period of four years.

\section{CASE REPORT}

A 60-year-old male was referred to our center by a dermatologist, having undergone punch biopsy of a lesion in suprapubic region. The patient gave a four year history of an enlarging lesion on the suprapubic area prior to presentation to the dermatologist, which had been treated with topical agents and antibiotics.

The lesion was scaly, pruritic in and above the genital area which appeared brown in colour with plaque like appearance (Figure 1) approximately $10 \mathrm{~cm}$ in size with elevated border having well defined margin and central atrophy and focal erosion. The lesion was clinically suspicious of Bowen's disease prompting for elliptical incision and histopathologic evaluation.

The patient had no other lumps or lymph nodes palpable anywhere in the rest of the body and no family history of similar disease. Co-morbidities like ischaemic heart disease, Alzheimer's disease and venous ulcer was not evident.

The specimen measured $7 \mathrm{X} 3 \mathrm{~mm}$ and contained skin covered soft tissue which was entirely submitted for histopathological evaluation. Light microscopy of hematoxylin and eosin stained sections showed intraepithelial proliferation of neoplastic; large, pale cells, located predominantly in the basal and parabasal layers of the epithelium (Figure 2). These atypical cells were also infiltrating into the follicular epithelium present in the dermis (Figure 2).

After discussion of available treatments, the patient opted for regular surveillance because the lesion was asymptomatic and slow growing. The patient has increasing intensity of itching and increase in size of the lesion after six months of diagnosis.

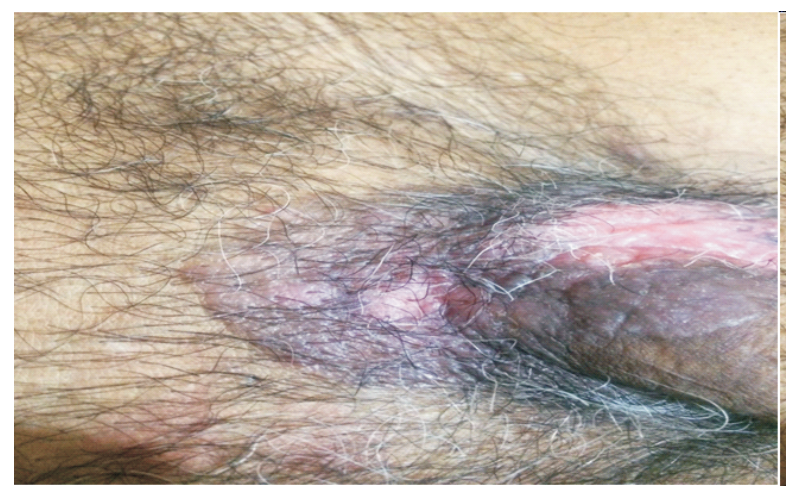

Figure1. Extramammary Pagets disease-Clinical appearance of the lesion

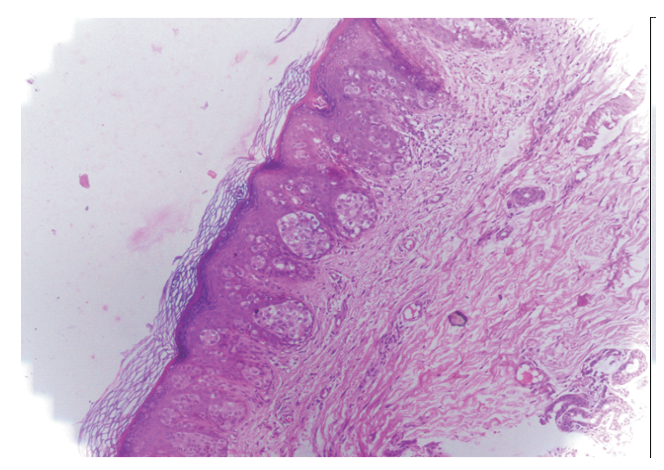

Figure 2. Extramammary Pagets disease- Intraepithelial proliferation of neoplastic; large, pale cells in the basal and parabasal layers of the epithelium ( $\mathrm{H \&}$ E)

\section{DISCUSSION}

EMPD is an intraepithelial adenocarcinoma arising in the apocrine glands of the skin. It accounts for $1 \%$ to $2 \%$ of vulvar cancers. ${ }^{4,5}$ EMPD occurs mainly among Caucasian women and Asian men in their $60 \mathrm{~s}$ and $70 \mathrm{~s} .{ }^{6}$

Since Dr. Croker described the first case of EMPD in 1889, no clear guidelines have been established for the diagnosis, treatment and follow-up of patients with EMPD. ${ }^{7}$ Especially, there have been few documented studies of EMPD in Nepal.

On average, $25 \%$ of EMPD cases have associated neoplastic disease (in adnexal structures or in organs with a contiguous epithelial lining), although the frequency varies with the site of the disease. $^{8}$

The associated malignancies previously reported to occur with it are aforementioned. Twenty patients $(8.1 \%)$ possessed an internal malignancies when diagnosed with EMPD. The associated internal malignancies included prostate cancer $(2$ 
cases), liver cancer ( 2 cases), colon cancer ( 2 cases), stomach cancer ( 2 cases), thyroid cancer ( 1 case), lung cancer (1 case), basal cell carcinoma ( 1 case), testicular cancer (1 case), and parotid gland cancer ( 1 case). These cases were considered as secondary EMPD.? Additionally, with the use of betaultrasonic examination, nearly one-third of the patients were found to have cysts, including simple hepatic cysts (27 cases), simple renal cysts (21 cases), hepatic and renal cysts (16 cases) and testicular and epididymal cysts ( 9 cases).

On average, diagnosis occurred 43.2 months after the onset of symptoms. Such a long delay may be attributed to the relatively ordinary initial symptoms of pruritus, rash, and erythema. These nonspecific clinical manifestations can be misdiagnosed as skin eczema or mycosis. Additionally, the physicians often lack of enough awareness of Paget's disease due to its rarity, and physical examination of the genital areas is frequently not as thorough as other areas. Accordingly, EMPD should always be in the differential diagnostic consideration of patients with genital pruritus and rash, and a biopsy of skin lesions should be performed if the patient's symptoms cannot be improved. The inguinal lymph nodes were the most common localization of metastatic EMPD. Patients with metastases showed a relatively dismal outcome compared with non-metastatic EMPD. ${ }^{10} \mathrm{CK} 20$ is used to assist in distinguishing primary and secondary EMPD. 'Many studies report- EMA, CEA, CK7 and PAS showed high expression levels in most of the EMPD, so these protein markers can be used to aid in the diagnosis of EMPD. HER2/neu, Ki67, P53, CK20 and S100 exhibit various expression levels and analysis of these four markers and EMPD pathological features revealed a significant correlation between HER2/neu expression and invasive EMPD. HER2/neu usually shows expression in a portion of EMPD patients and the expression of this protein is significantly related to invasive EMPD. ${ }^{10}$ Molecular markers, such as HER2 or proliferation marker Ki-67, can be used as prognostic factors and for treatment selection. Combined chemotherapy with radiotherapy can be used for patients with systemic nodal metastases. ${ }^{10}$

On the other hand, HER2/neu is also an important biomarker for targeted therapy. This indicates targeted inhibition of HER2/neu may be used for treatment of some types of intractable EMPD with HER2/ neu expression. ${ }^{8,10}$

\section{CONCLUSION}

EMPD is extremely rare entity. A high index of suspicion, combined with histological examination is essential to accurate diagnosis. The treatment of choice is surgery. Longterm follow-up is mandatory in these patients in order to identify and treat any subsequent recurrence or concurrent malignancy.

\section{CONFLICT OF INTEREST}

None

\section{REFERENCES}

1. Lopes Filho LL, Lopes IMRS, Lopes LRS, Enokihara MMSS, Michalany AO, Matsunaga N. Mammary and extramammary Paget's disease. An Bras Dermatol. 2015;90(2):219-31.

2. O'Keefe R. Lever's Histopathology of the Skin. 11th ed. Elder E D, editor. Vol. 46, Australasian Journal of Dermatology. Philadelphia: Wolters Kluwer; 2005. 286-286 p.

3. DeLellis R a, Williams ED. World Health Organization Classification of Tumours 2004. World Heal Organ Classif tumors Pathol Genet Tumors Endocr Organs. 2004;8:49-133.

4. Shepherd, Vohn Davidson, Eltor john Davies-Humphrey J. Extramammary Paget's disease. $\mathrm{Br} \mathrm{J}$ Obs Gynaecol. 2005;112:273.

5. Cohen PR, Schulze KE, Tschen JA, Hetherington GW, Nelson BR. Treatment of extramammary Paget disease with topical imiquimod cream: Case report and literature review. South Med J .2006;99(4):396-402.

6. Wagner, Goose Sachse MM. Extramammary Paget disease clinical appearance, pathogenesis, management. J Dtsch Dermatol Ges. 2011;9:448-54.

7. Zhang N, Gong K, Zhang X, Yang Y, Na Y. Extramammary Paget's disease of scrotum-report of 25 cases and literature review. Urol Oncol Semin Orig Investig. 2010;28(1):28-33 .

8. Goldblum JR, Hart WR. Vulvar Paget's disease: A clinicopathologic and immunohistochemical study of 19 cases. Am J Surg Pathol. 1997;21(10):1178-87.

9. Kang Z, Zhang Q, Zhang Q, Li X, Hu T, Xu X, et al. Clinical and pathological characteristics of extramammary Paget's disease: Report of 246 Chinese male patients. Int J Clin Exp Pathol. 2015;8(10):13233-40.

10. Hatta N, Yamada M, Hirano T, Fujimoto A, Morita R. Extramammary Paget's disease: Treatment, prognostic factors and outcome in 76 patients. Br J Dermatol. 2008;158(2):313-8. 